\title{
Pengembangan E-Modul Praktikum Fisika Dasar 1 dengan Pendekatan STEM untuk Menumbuhkan Kemandirian Belajar
}

\author{
Desy Kumala Sari \\ Universitas Musamus \\ sari_fkip@unmus.ac.id
}

\section{Article History}

received 23/4/2021

revised 30/4/2021

accepted 9/5/2021

\begin{abstract}
The experiment activities of fundamental physics in the laboratory become challenging during Covid 19 Pandemic. The experiment should be carried out remotely, and there is a need to develop an electronic practicum module containing an interactive tutorial video. The research aims to create an electronic module of Fundamental Physics I Experiment with STEM (Science, Technology, Engineering, and Mathematics) Approach. The used development model was $4 D$ (Define, Design, Develop, and Disseminate). The collected data instruments are expert validation questionnaire, practicality questionnaire, and independence questionnaire to determine the product effectivity. The validation questionnaires were rated by expert and the practicality questionnaire were by students as experiment participants. Ideal Standard Deviation analyzed data to comprehend its category. The interpreted result showed the product feasible, practices, and effective to use in the learning process. The average feasibility score is 71 , and the practicality aspect has a score of 38. Both of them have excellent criteria. Besides that, the developed product also improves students' autonomy in experimental activities.
\end{abstract}

Keywords: Experiment, Physics, STEM, Learning Independence

\begin{abstract}
Abstrak
Pelaksanaan praktikum dimasa pandemi Covid-19 menjadi tantangan sendiri dalam matakuliah Fisika Dasar. Pelaksanaan praktikum dituntut untuk dilaksanakan lebih mandiri, sehingga perlu dikembangkan suatu modul praktikum berbasis elektronik dengan memuat video tutorial yang interaktif. Penelitian ini bertujuan untuk mengembangkan E-modul Praktikum Fisika Dasar I dengan menggunakan pendekatan STEM. Model pengembangan yang digunakan dalam penelitian ini yakni 4D (Define, Design, Develop, and Disseminate). Instrumen penelitian yang digunakan berupa angket telaah, angket kepraktisan, dan angket kemandirian. Angket telaah diisi oleh penelaah, serta angket kepraktisan dan kemandirian diisi oleh mahasiswa peserta praktikum. untuk mengetahui keefektifan produk. Data hasil penelitian dianalisis menggunakan teknik Simpangan Baku Ideal (SBi). Hasil analisis menunjukkan bahwa produk yang dikembangkan memenuhi kriteria layak, praktis dan efektif. Rata-rata skor kelayakan produk sebesar 71 yang berada pada kategori "sangat baik", selanjutnya rata-rata skor kepraktisan produk sebesar 38 yang juga berada pada kategori "sangat baik". Selain itu juga disimpulkan bahwa produk yangdikembangkan dapat menumbuhkan kemandirian melaksanakan praktikum mahasiswa jurusan fisika.
\end{abstract}

Kata kunci: Praktikum, Fisika, STEM, Kemandirian Belajar 


\section{PENDAHULUAN}

Praktikum merupakan bagian penting dalam pembelajaran. Sesuai dengan Kamus Besar Bahasa Indonesia (KBBI), praktikum didefinisikan sebagai kegiatan yang memiliki tujuan agar peserta didik dapat menguji dan melaksanakan untuk memperoleh pengalaman langsung terkait teori yang di peroleh dalam pembelajaran. Salah satu matakuliah yang selalui disertakan dengan kegiatan praktikum yakni Fisika. Pengembangan ilmu fisika selalu didasarkan pada kegiatan praktikum atau eksperimen tujuannya untuk membuktikan kebenaran konsep fisika (Hidayatullah et al., 2021). Hakikat fisika sebagai ilmu didefinisikan sebagai proses produk, maupun sikap yang merupakan hasil dari pengalaman langsung (D. K. Sari et al., 2018). Hasil tersebut diperoleh dengan mengamati gejala alam yang muncul serta dikaitkan dengan teori yang sudah ada (Pri Ariadi Cahya Dinata et al., 2017). Pengalaman langsung dalam pembelajaraan fisika dapat diperoleh dengan metode praktikum atau eksperimen (Pujani, 2015). Pentingnya pengalaman langsung ini dapat meningkatkan kemampuan mengingat peserta didik sebanyak $70 \%$ lebih banyak dibandingkan dengan metode ceramah (Amrullah et al., 2017).

Pelaksanaan kegiatan praktikum membutuhkan modul praktikum sebagai penuntun agar kegiatan dapat berjalan sesuai dengan prosedurnya. Modul praktikum memuat tata cara persiapan, pelaksanaan, analisis data dan juga pelaporan (P. A.C. Dinata, Rasidah, Wardhana, et al., 2021). Kegiatan praktikum dilaksanakan di sebuah laboratorium yang sudah disesuaikan dengan kebutuhan praktikum (P. A.C. Dinata, Rasidah, Wardhana, et al., 2021). Misalnya untuk melaksanakan praktikum polarisasi diperlukan laboratorium yang gelap. Tujuannya agar pola cahaya hasil polarisasi dapat dilihat dengan jelas. Praktikum Fisika Dasar 1 untuk mahasiswa Jurusan Pendidikan Fisika di Universitas Musamus dilaksanakan di Laboratorium Pendidikan Fisika.

Wawancara dengan laboran Laboratorium Pendidikan Fisika memberikan informasi bahwa walaupun telah tersedia modul praktikum, pelaksanaan praktikum membutuhkan waktu lebih lama untuk menjelaskan prosedur praktikum kepada mahasiswa. Selain itu, minat mahasiswa dalam membaca modul praktikum sangat kurang, sehingga dalam pelaksanaan praktikum hanya sebagian kecil mahasiswa yang telah mengerti prosedur pelaksanaan praktikum. Mahasiswa juga sering lupa membawa modul pada saat praktikum. Wawancara dengan mahasiswa memberikan informasi bahwa ukuran modul yang cukup besar sehingga membutuhkan ruang agar dapat di bawa kemana aja. Mahasiswa kurang mengerti prosedur praktikum dikarenakan alat-alat yang digunakan tidak familiar sehingga ketika melaksanakan praktikum masih merasa kebingungan.

Permasalahan lain muncul terutama di masa pandemi Covid-19 ini, kegiatan praktikum menjadi sangat terbatas. Pelaksanaan praktikum yang membutuhkan kerja sama harus diperhatikan dengan menjaga jarak dan sesuai dengan protokol kesehatan yang berlaku (Setiaji \& Dinata, 2020). Oleh karena itu, peserta didik dituntut untuk lebih mandiri dalam mempelajari modul praktikum agar ketika pelaksanaan praktikum lebih menghemat waktu dan dapat sesuai dengaan protokol kesehatan (Desy Kumala Sari et al., 2020). Solusi yang dapat diberikan untuk mempermudah mahasiswa dalam mempelajari modul praktikum dengan mudah dan dapat diakses kapan saja dan dimana saja (Misbah et al., 2021) dengan membuat modul dalam bentuk elektronik (emodul). Modul jenis ini dapat di operasikan menggunakan smartphone, $P C$, tablet dan juga komputer tergantung pembaca yang digunakan (D. Sari et al., 2019). E-modul memiliki keunggulan karena dapat menampilkan teks, gambar, animasi, dan juga video (P. A.C. Dinata, Rasidah, Wardhana, et al., 2021). Penggunaan e-modul juga dapat mengurangi penggunaan kertas (P. A.C. Dinata, Rasidah, \& Wardhana, 2021; Desy Kumala Sari et al., 2021). Penelitian ini di fokuskan pada pembuatan e-modul didasarkan pada hasil observasi bahwa sebagain besar mahasiswa jurusan pendidikan fisika memiliki smartphone dan dapat mengoperasikannya dengan baik. E-modul yang 
baik harus memenuhi persyaratan sistematika yang sesuai, dengan tampilan yang menarik sehingga mahasiswa berminat untuk mempelajari serta mudah dibawa kemana saja.

Pengembangan e-modul praktikum dapat dikembangkan dengan pendekatan STEM (science, technology, engineering, and mathematics). E-modul praktikum berbasis STEM dapat membentuk karakter dari mahasiswa (Sartika, 2019) melalui pengenalan konsep (science) dan menerapkan konsep tersebut melalui keterampilan (technology) dengan tujuan untuk merancang dengan cara tertentu (engineering) kemudian dianalisis berdasarkan perhitungan matematis (mathematics). Pendekatan STEM ini dapat mempermudah mahasiswa dalam melaksanakan kegiatan praktikum (Permanasari, 2016). Modul praktikum juga dapat dilengkapi dengan video tutorial penggunaan alat untuk mempermudah mahasiswa dalam mempelajari prosedur praktikumnya (Pujani, 2015). Dengan demikian penelitian ini difokuskan pada perancangan dan pembuatan e-modul praktikum dengan pendekatan STEM untuk mata kuliah Fisika Dasar 1.

\section{METODE}

Pelaksanaan penelitian ini berdasarkan metode penelitian dan pengembangan dengan model 4D. Model ini terdiri dari 4 tahapan yakni define, design, develop, dan disseminate (Thiangrajan et al., 1974; Usmeldi et al., 2017). Suatu produk baru yang dikembangkan baiknya memenuhi standar yang ada. Poduk dikatakan baik jika memenuhi standar kelayakan, kepraktisan, dan keefektifan (Nieveen, 1999; Yektyastuti \& Ikhsan, 2016). Responden yang terlibat dalam penelitian ini yakni 7 penelaah dan 19 mahasiswa jurusan pendidikan fisika. Penelaah yang terlibat adalah dosen pendidikan fisika dari beberapa universitas yang mengampu mata kuliah Fisika Dasar 1. Kriteria mahasiswa yang dijadikan responden adalah mahasiswa yang telah dan sedang mengikuti kegiatan praktikum fisika dasar 1. Instrumen yang digunakan untuk memperoleh data yakni angket berupa angket telaah dan juga angket kepraktisan produk. Angket telaah terdiri dari 16 pernyataan yang memuat aspek materi, bahasa dan media. Angket kepraktisan terdiri dari 9 pernyataan dengan memuat aspek kebermanfaatan produk dalam pembelajaran. Angket Kemandirian terdiri dari 15 pernyataan dengan indikator kemandirian belajar. Skala yang digunakan dalam angket telaah dan kepraktisan yakni skala likert dengan 5 (lima) kriteria jawaban. Data yang diperoleh kemudian dianalisis menggunakan teknik simpangan baku ideal (SBi) dan diinterpretasikan sesuai dengan Tabel 1 (Widoyoko, 2009). Sedangkan angket kemandirian belajar menggunakan empat skala yakni "sangat mandiri", "mandiri", "cukup mandiri" dan "tidak mandiri".

Tabel 1. Kriteria kualitas produk

\begin{tabular}{cc}
\hline Rentang Skor & Kriteria \\
\hline $\bar{x} \geq x_{1}+1.8 \mathrm{SB}_{\mathrm{i}}$ & Sangat Baik \\
$x_{1}+0.6 \mathrm{SB}_{\mathrm{i}} \leq \bar{X} \leq x_{1}+1.8 \mathrm{SB}_{\mathrm{i}}$ & Baik \\
$x_{1}-0.6 \mathrm{SB}_{\mathrm{i}} \leq \bar{X} \leq x_{1}+0.6 \mathrm{SB}_{\mathrm{i}}$ & Cukup Baik \\
$x_{1}-1.8 \mathrm{SB}_{\mathrm{i}} \leq \bar{x} \leq x_{1}+0.6 \mathrm{SB}_{\mathrm{i}}$ & Kurang Baik \\
$\bar{x} \geq x_{1}-1.8 \mathrm{SB}_{\mathrm{i}}$ & Tidak Baik \\
\hline
\end{tabular}

Produk yang dikembangkan dapat dinyatakan baik untuk digunakan dalam penbelajaran fisika jika memenuhi kriteria "sangat baik" dan "baik". 


\section{HASIL DAN PEMBAHASAN}

Pelaksanaan penelitian dimulai dari tahap awal atau disebut dengan tahap define terdiri dari beberapa kegiatan yakni menganalisis kebutuhan untuk menemukan permasalahan yang dihadapi, selnjutnya dilakukan kajian literatur untuk menemukan solusi yang dapat diambil dalam menyelesaikan permasalahan yang ditemui. Berdasarkan hasil analisis kebutuhan, ditemukan masalah bahwa belum tersediannya modul yang dapat memberikan ilustrasi prosedur praktikum yang mudah di pahami serta mudah dibawa kemana saja sebagai media belajar mandiri. Permasalahan ini kemudian menyebabkan mahasiswa belum sepenuhnya memahami prosedur praktikum pada saat pelaksanaan praktikum. Selain itu, dengan modul yang tidak mudah dibawa kemana saja menyebabkan mahasiswa terkadang lupa membawa modul ketika kegiatan praktikum. Permasalahan ini kemudian di analisis dan di lakukan kajian litertur yang kemudian diberikan solusi dengan membuat sebuah modul praktikum berbasis elektronik dengan menggunakan pendekatan STEM.

Tahap selanjutnya adalah design. Tahap ini merupakan tahap mempersiapkan semua konten produk yang akan dikembangkan, maupun kisi-kisi instrumen penelitian yang akan digunakan. Pada tahap ini dikembangkan konten modul berupa petunjuk praktikum fisika dasar 1 serta skenario video tutorial yang akan dikembangkan agar mempermudah mahasiswa dalam pelaksanaan praktikum. Panduan praktikum yang dipersiapkan memuat judul modul, daftar isi, kata pengantar, tata tertib praktikum, judul praktikum, tujuan praktikum, kajian teori, alat dan bahan, prosedur praktikum, hasil pengamatan, tugas pendahuluan, serta daftar pustaka (P. A.C. Dinata, Rasidah, Wardhana, et al., 2021).

Persiapan pengembangan produk dilaksanakan pada tahap sebelumnya kemudian dilanjutkan pada tahap pengembangan. Pada tahap ini dimulai dengan membuatan video tutorial praktikum sesuai dengan skenario video yang telah dibuat pada tahap selanjutnya. Video yang sudah jadi kemudian digabungkan dengan konten yang telah disusun pada tahap selanjutnya yang di padukan dalam elektronik modul dengan menggunakan software sigil. Pembuatan e-modul ini tergolong mudah karena penggunaan software sigil yang cukup mudah dengan mengubah ekstensi file .doc pada konten yang dibuat menjadi ekstensi .html. File dalam ekstensi .html ini kemudian di masukkan kedalam software sigil yang kemudian dirapikan dan ditambahkan gambar maupun video serta pembuatan daftar isi otomatis. Perlu diketahui bahwa penggunaan rumus dalam software sigil harus berupa gambar agar tersusun lebih rapi. Produk akhir E-modul ini dalam ekstensi .EPUB sehingga perlu pembaca khusus agar mempermudah mahasiswa dalam memutar video tutorial. Tampilan cover E-Modul Praktikum Fisika Dasar I yang dikembangkan disajikan pada Gambar 1. 


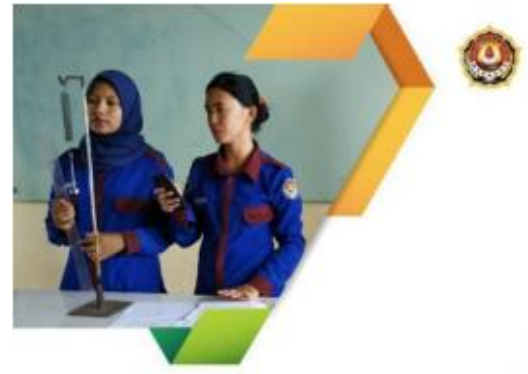

\section{E-Module Praktikum Fisika Dasar I}

\section{Gambar 1. Cover E-Modul Praktikum Fisika Dasar I}

E-modul ini memuat konten berupa beberapa panduan praktikum yakni, pengukuran dasar listrik, bandul matematis, pegas, dan viskositas. Masing-masing panduan terdiri dari judulpraktikum, tujuan praktikum, alat, metodologi dasar, prosedur kerja, latihan soal, sumber pustaka, hasil pengamatan, dan perhitungan. Tampilan konten E-Modul Praktikum Fisika Dasar I dapat dilihat pada Gambar 2.
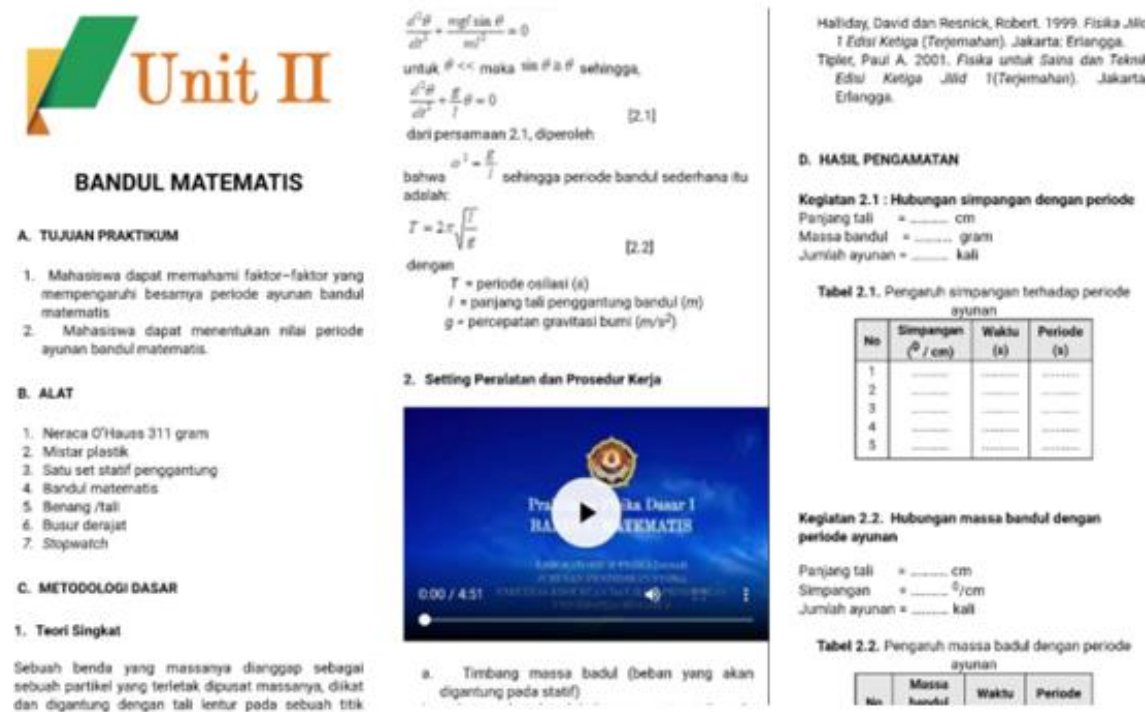

Gambar 2. Tampilan Konten E-Modul Praktikum Fisika Dasar I

Produk yang sudah dikembangkan kemudian dilakukan uji kelayakan dengan meminta penilaian 7 orang penelaah. Angket yang diberikan pda penelaah terdiri dari 16 pernyataan yang memuat aspek materi, bahasa dan media. Berdasarkan hasil analisis keseluruhan produk, diperoleh informasi bahwa rata-rata skor yang diberikan penelaah sebesar 71 . Sesuai dengan kriteria e-modul yang dikembangkan pada Tabel 2, diperoleh informasi bahwa modul yang dikembangkan berada pada kategori sangat baik sehingga dapat disimpulkan bahwa modul layak diujicobakan pada responden. 
Tabel 2. Kriteria Kelayakan E-Modul Praktikum Fisika Dasar 1

\begin{tabular}{cc}
\hline Rentang Skor & Kriteria \\
\hline $\bar{x} \geq 67.21$ & Sangat Baik \\
$54.40 \leq \bar{X} \leq 67.21$ & Baik \\
$41.60 \leq \bar{X} \leq 54.40$ & Cukup Baik \\
$28.79 \leq \bar{X} \leq 41.60$ & Kurang Baik \\
$\bar{x} \geq 28.79$ & Tidak Baik \\
\hline
\end{tabular}

Selain itu, dikaji berdasarkan aspeknya, yakni aspek materi, bahasa dan media, diperoleh informasi bahwa rata-rata skor yang diperoleh dari penelaah untuk aspek materi sebesar 23.6, aspek bahasa sebesar 23.7, dan aspek media sebesar 20.42. Hasil yang diperoleh di interpretasikan sesuai kriteria kelayakan berdasarkan aspeknya (Tabel 3) diperoleh informasi bahwa produk yang dikembangkan berada pada kategori "sangat baik" sehingga dinyatakan layak untuk diujicobakan pada responden.

Tabel 3. Kriteria Kelayakan E-Modul Praktikum Fisika Dasar 1 Berdasarkan Aspek

\begin{tabular}{cc}
\hline Rentang Skor & Kriteria \\
\hline$X>16.68$ & Sangat Baik \\
$13.56<X \leq 16.68$ & Baik \\
$10.44<X \leq 13.56$ & Cukup Baik \\
$7.32<X \leq 10.44$ & Kurang Baik \\
$X \leq 7.32$ & Tidak Baik \\
\hline
\end{tabular}

Walaupun dinyatakan layak, berdasarkan masukan dari penelaah perlu dilakukan beberapa revisi lanjutan untuk penyempurnaan produk agar menjadi lebih baik. Secara umum, masukan yang diberikan penelaah yakni sebaiknya alat yang ditampilkan juga berupa gambar, serta perlu ditambahkan persamaan $R_{\text {total }}$ pada teori praktikum pengukuran dasar listrik. Hasil revisi disajikan pada Gambar 3.

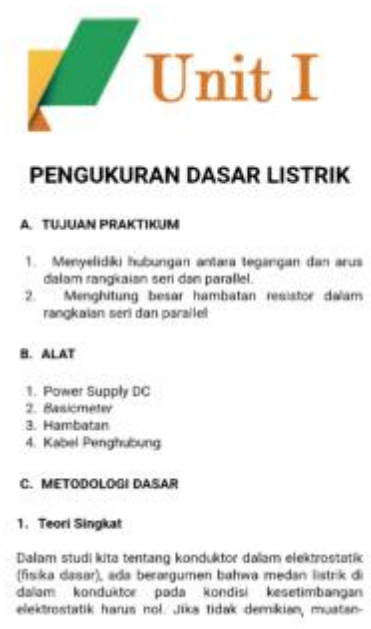

(a)

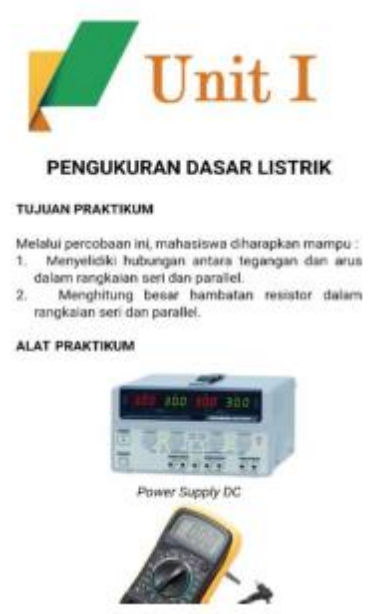

(b)

Gambar 3. (a) sebelum revisi; (b) penambahan gambar setelah revisi

Berdasarkan masukan penelaah, produk direvisi dengan menambahakan gambar beserta keterangannya. Tujuan penambahan gambar ini untuk mempermudah mahasiswa untuk mengenal alat yang digunakan dalam kegiatan praktikum. Revisi 
selanjutnya terkait penambahan pada konten teori praktikum. Hasil revisi disajikan pada Gambar 4.

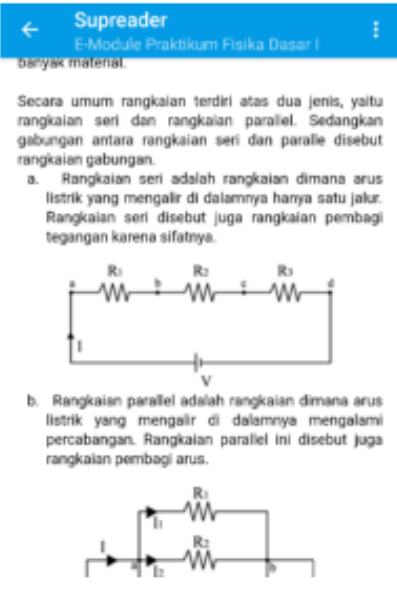

(a)

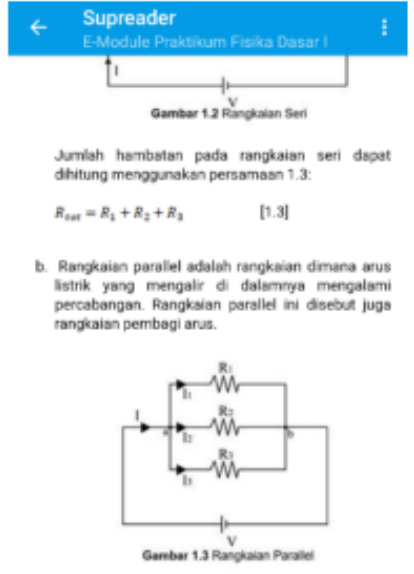

(b)

Gambar 4. (a) sebelum revisi; (b) penambahan persamaan $\mathbf{R}_{\text {total }}$

Setelah produk dinyatakan layak untuk di ujicobakan pada responden, kemudian dilakukan proses uji kepraktisan pada 19 mahasiswa jurusan pendidikan fisika semester 1. Peserta didik diarahakan untuk mendownload e-modul praktikum fisika dasar I, kemudian peserta diberi waktu untuk mempelajari e-modul dan selanjutnya diminta untuk melaksanakan praktikum di laboratorium. Rata-rata hasil penilaian mahasiwa terhadap e-modul praktikum fisika dasar I yang digunakan sebesar 38 . Sesuai dengan kriteria kepraktisan produk (Tabel 4), diperoleh informasi bahwa produk yang dikembangkan berada pada kategori "sangat baik", sehingga dinyatakan memenuhi kriteria kepraktisan (Desy Kumala Sari, 2020) dan dapat digunakan dalam kegiatan praktikum fisika dasar I.

Tabel 4. Kriteria Kepraktisan E-Modul Praktikum Fisika Dasar 1

\begin{tabular}{cc}
\hline Rentang Skor & Kriteria \\
\hline $\bar{x} \geq 37.8$ & Sangat Baik \\
$30.6 \leq \bar{X} \leq 37.8$ & Baik \\
$23.4 \leq \bar{X} \leq 30.6$ & Cukup Baik \\
$16.2 \leq \bar{x} \leq 23.4$ & Kurang Baik \\
$\bar{x} \geq 16.2$ & Tidak Baik \\
\hline
\end{tabular}

Sesuai dengan saran yang diberikan mahasiswa pada pelaksanaan uji kepraktisan produk, maka tabel hasil pengamatan diberikan warna agar terlihat lebih menarik. Hasil revisi disajikan pada Gambar 5. 


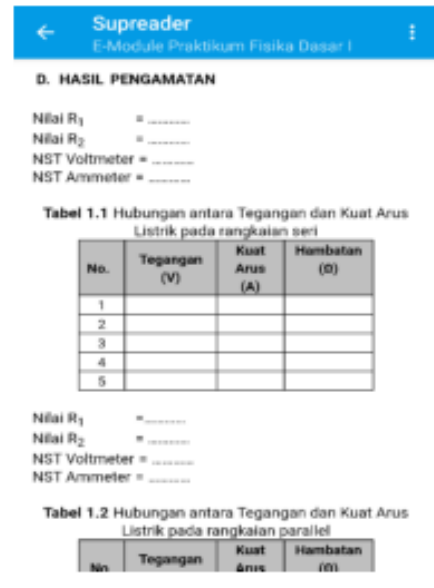

(a)

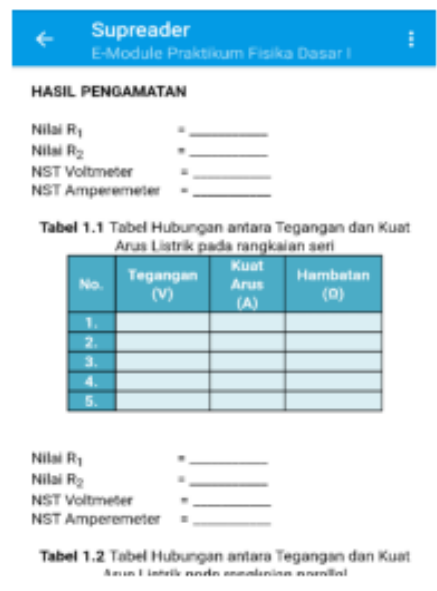

(b)

Gambar 5. (a) sebelum revisi; (b) pemberian warna pada tabel pengamatan

Data kemandirian mahasiswa dalam melaksanakan praktikum menggunakan emodul praktikum fisika dasar I diperoleh dari angket yang diisi setelah pelaksanaan praktikum selesai. Hasil kemandirian mahasiswa disajikan pada Tabel 5.

Tabel 5. Kriteria Kepraktisan E-Modul Praktikum Fisika Dasar 1

\begin{tabular}{ccc}
\hline No & Rentang Skor & $\begin{array}{c}\text { Jumlah } \\
\text { Responden }\end{array}$ \\
\hline 1 & Sangat Mandiri & 8 \\
2 & Mandiri & 11 \\
3 & Cukup Mandiri & 0 \\
4 & Tidak Mandiri & 0 \\
\hline & Jumlah & 19 \\
\hline
\end{tabular}

Berdasarkan hasil analisis maka disimpulkan bahwa mahasiswa menggunakan emodul praktikum Fisika Dasar I adalah mandiri dan sangat mandiri. Hal ini menunjukkan bahwa e-modul praktikum Fisika Dasar I dapat menumbuhkan kemandirian belajar mahasiswa yang telah memenuhi indikator kemandirian belajar (Amrullah et al., 2017). Indikator yang dimaksud yakni mahasiswa memiliki sifat percaya diri, motivasi, inisiatif, disiplin dan tanggung jawab.

Produk yang telah dinyatakan layak untuk digunakan karena telah memenuhi kriteria kelayakan menurut penelaah, kriteria kepraktisan menurut mahasiswa, dan juga kriteria keefektifan dalam menumbuhkan kemandirian belajar, kemudian di sebarluaskan sesuai dengan tahap disseminate. Produk ini pertamakali dipresentasikan pada rapat jurusan pendidikan fisika yang kemudian di berikan kepada laboran untuk ditindaklanjuti penggunaannya dalam kegiatan praktikum Fisika Dasar I. Panduan pengunaan e-modul yang dikembangkan dapat di akses menggunakan link http://bit.ly/PANDUemodulePFDI atau dengan menscan barcode pada Gambar 6 . 


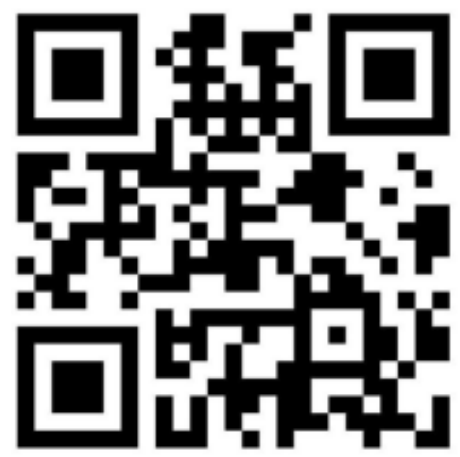

\section{Gambar 6. Barcode Buku Panduan E-Modul Praktikum Fisika Dasar I}

Hasil penelitian ini menunjukkan bahwa produk yang dikembangkan berupa emodul praktikum fisika dasar I telah memenuhi kriteria layak dan praktis. Sesuai dengan kriteria produk yang baik, Nieveen (1999) mengungkapkan kriteria yang harus dipenuhi yakni kelayakan, kepraktisan dan keefektifan. Dengan demikian produk ini dapat digunakan dalam praktikum fisika dasar 1. E-modul ini dapat membantu mahasiswa dalam melaksanakan praktikum mandiri. Pramana \& Dewi (2014) dalam tulisannya juga mengungkapkan bahwa penggunaan media pembelajaran secara elektronik dapat menumbuhkan kemandirian belajar. Kemandirian belajar yang tumbuh dapat berupa (Pramana \& Dewi, 2014) sifat percaya diri, motivasi, inisiatif, disiplin dan tanggung jawab.

\section{SIMPULAN}

E-modul Praktikum Fisika Dasar I dinyatakan telah memenuhi kriteria kelayakan, kepraktisan, dan keefektifan sehingga produk ini layak untuk digunakan dalam praktikum Fisika Dasar I. Produk ini memiliki keunggulan dibanding modul yang lain karena memiliki video tutorial yang interaktif sehingga dapat membantu peserta didik dalam melaksanakan praktikum fisika dasar secara mandiri. E-modul ini berekstensi .EPUB sehingga perlu di buka dengan pembaca khusus yang banyak tersedia secara online. Penggunaan pembaca khusus ini sangat membantu mahasiswa agar tidak susah mencari file yang ingin dibuka karena langsung terdeteksi oleh pembaca dan juga langsung muncul berupa cover e-book.

Kelajutan penelitian ini sebaiknya dapat diujicobakan pada mahasiswa dalam skala besar. Pelaksanaan ujicoba skala besar dalam penelitian ini belum dapat dilkasanakan karena responden yang terbatas. Selain itu, perlu juga dikembangkan emodul untuk praktikum-praktikum matakuliah lain yang dapat menunjang pembelajaran mandiri selama masa pandemi maupun pra pandemi Covid 19.

\section{DAFTAR PUSTAKA}

Amrullah, A., Sari, D. K., \& Putri, J. K. (2017). The impact of E-Module assisted by scaffolding based android by using plickers on the achievement of understanding concepts and student independency. 3rd International Seminar on Science Education, 93-97.

Dinata, P. A.C., Rasidah, \& Wardhana, V. W. (2021). The Validity of Electronic Practicum Module Based on Scientific Argumentation for Practicum Media during COVID-19 Pandemic. Journal of Physics: Conference Series, 1805(1). https://doi.org/10.1088/1742-6596/1805/1/012022

Dinata, P. A.C., Rasidah, Wardhana, V. W., \& Misbah. (2021). Electronic practicum module based on scientific argumentation as a practicum medium of motion and force in the covid-19 pandemic. Journal of Physics: Conference Series, 1760(1). 
https://doi.org/10.1088/1742-6596/1760/1/012003

Dinata, Pri Ariadi Cahya, Sastradika, D., \& Safitri, A. D. (2017). Implementation of Gasing Learning in ARCS Learning Strategy to Enhance Students' Motivation in 9th Grade of Indonesian Junior High-School. IJPTE : International Journal of Pedagogy and Teacher Education, 1(2), 80-92. https://doi.org/10.20961/ijpte.v1i2.15286

Hidayatullah, Z., Wilujeng, I., Nurhasanah, N., Gusemanto, T. G., \& Makhrus, M. (2021). Synthesis of the 21st Century Skills (4C) Based Physics Education Research In Indonesia. JIPF (Jurnal IImu Pendidikan Fisika), 6(1), 88. https://doi.org/10.26737/jipf.v6i1.1889

Misbah, M., Sasmita, F. D., Dinata, P. A. C., Deta, U. A., \& Muhammad, N. (2021). The validity of introduction to nuclear physics e-module as a teaching material during covid-19 pandemic. IOP Conference Series: Earth and Environmental Science, 1796(1). https://doi.org/10.1088/1742-6596/1796/1/012070

Nieveen, N. (1999). Prototyping to Reach Product Quality. In J. van den Akker, R. M. Branch, K. Gustafson, N. Nieveen, \& T. Plomp (Eds.), Design Approaches and Tools in Education and Training (p. 296). Springer-Science+Businnes MEdia, B.V. https://doi.org/10.1007/978-94-011-4255-7_1

Permanasari, A. (2016). STEM education : inovasi dalam pembelajaran sains. Seminar Nasional Pendidikan Sains, 23-34.

Pramana, W. D., \& Dewi, N. R. (2014). Pengembangan E-Book IPA Terpadu Tema Suhu Dan Pengukuran Untuk Menumbuhkan Kemandirian Belajar Siswa. USEJ Unnes Science Education Journal, 3(3). https://doi.org/10.15294/usej.v3i3.4267

Pujani, N. M. (2015). Pengembangan Perangkat Praktikum Ilmu Pengetahuan Bumi dan Antariksa Berbasis Kemampuan Generik Sains untuk Meningkatkan Keterampilan Laboratorium Calon Guru Fisika. JPI (Jurnal Pendidikan Indonesia), 3(2), 471-484. https://doi.org/10.23887/jpi-undiksha.v3i2.4463

Sari, D. K., Supahar, \& Ralmugiz, U. (2018). The Influence of Android-Based Isomorphic Physics (FORFIS) Application on Analogical Transfer and SelfDiagnosis Skill of Students at SMA Negeri 3 Kupang. Jurnal Pendidikan IPA Indonesia, 7(2), 154-161. https://doi.org/10.15294/jpii.v7i2.14268

Sari, D., Simbolon, M., \& Reski, A. (2019). Utilization Isomorphic Physics (FORFIS) Application to Improve Physics Analogical Transfer Skill of Senior High School Students. 2nd International Conference on Social Science (ICSS 2019), 383, 109112. https://doi.org/10.2991/icss-19.2019.206

Sari, Desy Kumala. (2020). Kepraktisan Aplikasi Fisika Isomorfis (Forfis) Berbasis Android dalam Menunjang Pembelajaran Mandiri. Diffraction, 2(1), 24-29. https://doi.org/10.37058/diffraction.v2i1.1669

Sari, Desy Kumala, Bahri, S., Simbolon, M., Nikat, R. F., \& Dinata, P. A. C. (2020). Pembelajaran Daring Berbantuan Whatsapp Pada Matakuliah Metodologi Penelitian Pendidikan Fisika. Musamus Journal of Science Education, 3(1).

Sari, Desy Kumala, Uspayanti, R., \& Dinata, P. A. C. (2021). Provision of Physics Props and Bilingual E-Book for SMA YPK Merauke. Mattawang: Jurnal Pengabdian Masyarakat, 2(2).

Sartika, D. (2019). Pentingnya pendidikan berbasis STEM dalam kurikulum 2013. Jurnal IImu Sosial Dan Pendidikan, 3(3), 89-93.

Setiaji, B., \& Dinata, P. A. C. (2020). Analisis kesiapan mahasiswa jurusan pendidikan fisika menggunakan e-learning dalam situasi pandemi Covid-19. Jurnal Inovasi Pendidikan IPA, 6(1), 59-70. https://doi.org/10.21831/jipi.v6i1.31562

Thiangrajan, S., Dorothy, S. S., \& Melvyn, I. S. (1974). Instructional development for training teaacher of exceptional children. Indiana University.

Usmeldi, Amini, R., \& Trisna, S. (2017). The development of research-based learning model with science, environment, technology, and society approaches to improve 
critical thinking of students. Jurnal Pendidikan IPA Indonesia, 6(2), 318-325. https://doi.org/10.15294/jpii.v6i2.10680

Widoyoko, E. P. (2009). Evaluasi program pembelajaran (S. Z. Qudsy (ed.)). Pustaka Pelajar.

Yektyastuti, R., \& Ikhsan, J. (2016). Pengembangan media pembelajaran berbasis android pada materi kelarutan untuk meningkatkan performa akademik siswa SMA. Jurnal Inovasi Pendidikan IPA, 2(1), 88.

https://doi.org/10.21831/jipi.v2i1.10289 